\title{
Whole-grain rye and wheat alkylresorcinols are incorporated into human erythrocyte membranes
}

\author{
Anna-Maria Linko* and Herman Adlercreutz \\ Institute for Preventive Medicine, Nutrition and Cancer, Folkhälsan Research Center and Division of Clinical Chemistry, P.O. Box 63, \\ University of Helsinki, FIN-00014, Helsinki, Finland
}

(Received 18 December 2003 - Revised 14 August 2004 - Accepted 22 August 2004)

\begin{abstract}
Alkylresorcinols (AR), a group of phenolic lipids, exist in the human diet in whole-grain rye and wheat. They are absorbed by humans and have been quantified in plasma. In this 2-week study we assessed AR incorporation into human erythrocyte membranes. Nine subjects attended the study; four avoided whole-grain products for 1 week and then included whole-grain rye and wheat bread in the diet for the second week, four included whole-grain rye and wheat products in the diet during the whole follow-up and one followed a gluten-free diet. Plasma and erythrocyte membrane AR were analysed after weeks 1 and 2. Erythrocyte membrane AR concentrations increased an average of $231 \mathrm{nmol} / 1$ of packed erythrocytes $(P=0 \cdot 036)$ after consumption of whole-grain rye and wheat products. Plasma AR levels increased an average of $175 \mathrm{nmol} / \mathrm{l}(P=0 \cdot 058)$. When intake of whole-grain products was constant, erythrocyte membrane and plasma AR levels remained stable. Long-chain AR were incorporated into erythrocyte membranes in a higher proportion compared to shorter-chain AR. This preliminary study shows that AR are incorporated into human erythrocyte membranes in vivo.
\end{abstract}

Alkylresorcinols: Whole grain: Erythrocyte membranes: Biomarkers

Intake of whole-grain products is generally recommended (Kantor et al. 2001), and is correlated to a lower risk of some chronic diseases such as diabetes, cardiovascular diseases and certain types of cancer (Slavin et al. 2001; Adlercreutz, 2002; Slavin, 2003). Alkylresorcinols (AR) are 1,3-dihydroxy-5-alkylbenzene derivatives with an odd-numbered alkyl chain, usually $\mathrm{C}_{17}$ to $\mathrm{C}_{25}$. In the human diet they are found in high amounts in bran fractions of rye $(360-3200 \mu \mathrm{g} / \mathrm{g}$ DM) and wheat $(317-1429 \mu \mathrm{g} / \mathrm{g})$ grains, and in smaller amounts in triticale and barley grains, but not in highly refined products (Ross et al. 2003c,d). The average percentages of $A R$ homologues $C_{17: 0}, C_{19: 0}, C_{21: 0}, C_{23: 0}$ and $C_{25: 0}$ are $24,32,25,10$ and $9 \%$ for rye and $5,33,48,10$ and $4 \%$ for wheat (Ross et al. 2003d). AR are absorbed by humans most probably from the upper intestine (Ross et al. 2003c), and have been quantified in human plasma (Linko et al. 2002).

In vitro studies show that $\mathrm{AR}$ are incorporated into biological membranes, where they can alter the membrane properties and function (Kozubek, 1987a; Kozubek \& Tyman, 1999). Depending on the chain length and saturation degree, they can change the permeability of erythrocyte membranes (Kozubek, 1987b; Kozubek \& Tyman, 1999). AR possess a concentration-dependent ability to alter the activities of membrane-bound enzymes (Kozubek et al. 1992). They could also have a role in oxidation reactions in membranes, although they seem to be rather weak antioxidants per se (Kamal-Eldin et al. 2001). Long-chain AR, compared to their shorter-chain homologues, are incorporated more easily into membranes and diffuse faster across them (Kozubek, 1989). The biological role of AR in humans is still undetermined, but it has been suggested that AR could serve as specific biomarkers of whole-grain intake (Ross et al. 2003b). The aim of this preliminary study was to provide more information about distribution and behaviour of AR in humans, and to show that whole-grain rye and wheat $\mathrm{AR}$ are incorporated into erythrocyte membranes in vivo.

\section{Materials and methods}

Nine volunteers attended the study. Four of them (Group I) avoided rye, wheat and barley products for 1 week and then continued for another week with their habitual Finnish diets, including wholegrain rye bread (average 3.5 pieces per d) and whole-grain wheat bread rich in AR ( 2 pieces per d). Four subjects (Group II) followed their normal diets with whole-grain rye ( 2 pieces per $\mathrm{d}$ ) and wholegrain wheat bread ( 2 pieces per d) for 2 weeks, and one subject maintained a gluten-free diet with no rye, wheat or barley products. The breads were commercially available whole-grain rye and wheat bread. Overnight fasting blood samples were drawn after the first (week 1) and the second (week 2) week of the experiment.

Plasma was separated by centrifugation and AR were analysed in plasma with a GC-MS method (Linko et al. 2002). Erythrocytes were analysed with a modified method for the analysis of vitamin $\mathrm{E}$, which has a molecular structure resembling that 
of AR (Bieri et al. 1979; Simon et al. 2001). Erythrocytes were separated from plasma by centrifugation and the cells were washed three times with $0 \cdot 15 \mathrm{M}-\mathrm{NaCl}-10 \mathrm{~mm}-\mathrm{Na}$-phosphate buffer, $\mathrm{pH} 7.4$, and made to a $50 \%$ hematocrit suspension. Samples were stored at $-20^{\circ} \mathrm{C}$ until analysis. An internal AR standard C20:0 (30 $\mu$ l), which does not naturally exist in grains (kindly provided by Prof. K. Wähälä, Department of Chemistry, University of Helsinki, Finland), was added to $3 \mathrm{ml}$ of suspension and proteins were denaturated with ice-cold methanol (Rathburn Chemicals, Walkerburn, UK) and vigorous shaking. AR were extracted twice with $10 \mathrm{ml} n$-heptane (Rathburn Chemicals), which was evaporated to dryness. Heptane, being more suitable with methanol extraction, was used as the extraction solvent instead of diethyl ether from the plasma method. Extraction solvents and extraction repeatability were tested previously with the plasma method development. Samples were dissolved into $0.5 \mathrm{ml}$ of methanol and purified with DEAE-Sephadex A-25 (Pharmacia Biotech AB, Uppsala, Sweden) in a free base form and analysed with the GC-MS as with the plasma method (Linko et al. 2002). All samples were analysed in duplicate, and a control plasma sample and a blank sample were included in every batch. Inter-series coefficient of variation was less than 10\%. We quantified saturated AR homologues C17:0, C19:0, $\mathrm{C} 21: 0, \mathrm{C} 23: 0$ and $\mathrm{C} 25: 0$. The results (nmol/l of packed erythrocytes or nmol/l of plasma) are expressed as total amounts of AR homologues and as an average of the study groups with their confidence intervals where appropriate. We performed all statistical analysis with SPSS 11.0.1 (SPSS Inc., Chicago, IL, USA) by a paired samples test $(95 \%$ CI). Differences were considered significant with a two-sided significance level of $P<0 \cdot 05$.
The Ethics Committee for the Department of Medicine, Hospital District of Helsinki and Uusimaa, Helsinki, Finland approved the study. All volunteers gave permission to publish the results.

\section{Results}

Table 1 shows the mean values of AR concentrations in plasma and erythrocyte membranes with their standard error of mean (SE) and range after week 1 and week 2 . The change (95\% CI) in the concentrations during the follow-up is also presented. We found no $\mathrm{AR}$ in plasma or erythrocyte membranes from the person following a gluten-free diet.

Table 2 shows mean percentages of AR C17:0, C19:0, C21:0, C23:0 and C25:0 with their range (95\% CI) in plasma and erythrocyte membranes calculated as an average from eight subjects after consuming whole-grain rye and wheat products for the second week of the study. The ratio of different AR homologues in plasma and erythrocyte membranes is also shown.

\section{Discussion}

As expected by the nature of lipophilic $\mathrm{AR}$ and in vitro studies, $\mathrm{AR}$ are incorporated into human erythrocyte membranes after whole-grain rye and wheat intake and can be quantified from the membranes. This is in agreement with earlier studies with rats, where AR were found in the adipose tissue and in low amounts in the blood cell fraction of whole blood (Ross et al. 2003a).

There was less individual variation in erythrocyte membrane AR concentrations than in plasma after avoiding whole-grain

Table 1. Plasma and erythrocyte membrane concentrations in Group I ( $n$ 4) and II ( $n$ 4) after weeks 1 and $2 \dagger$ (Mean values with their standard errors and range; also the increase $(95 \% \mathrm{Cl})$ in the concentrations during the follow-up)

\begin{tabular}{|c|c|c|c|c|c|c|}
\hline & \multicolumn{3}{|c|}{ Plasma (nmol/l) } & \multicolumn{3}{|c|}{ Erythrocytes (nmol// of packed cells) } \\
\hline & Mean & SE & Range & Mean & SE & Range \\
\hline \multicolumn{7}{|l|}{ Group I } \\
\hline Week 1 & $32 \cdot 4$ & $12 \cdot 2$ & $4 \cdot 4,55 \cdot 5$ & $17 \cdot 2$ & $2 \cdot 6$ & $13 \cdot 2,24 \cdot 3$ \\
\hline Week 2 & 207 & $54 \cdot 7$ & $56 \cdot 3,288$ & 248 & $65 \cdot 7$ & 136,436 \\
\hline Increase & $175^{\star}$ & $58 \cdot 3$ & $6 \cdot 36,269$ & $231^{\star *}$ & 63.7 & 119,412 \\
\hline \multicolumn{7}{|l|}{ Group II } \\
\hline Week 1 & $37 \cdot 8$ & $15 \cdot 4$ & $10 \cdot 8,69 \cdot 0$ & $62 \cdot 5$ & $25 \cdot 8$ & $16 \cdot 7,136$ \\
\hline Week 2 & $41 \cdot 2$ & 23.5 & $11 \cdot 0,110$ & $69 \cdot 6$ & $17 \cdot 7$ & $25 \cdot 8,107$ \\
\hline Increase & $3.44 \mathrm{NS}$ & $14 \cdot 3$ & $-28 \cdot 2,41 \cdot 2$ & $7.01 \mathrm{NS}$ & 14.9 & $-29 \cdot 5,43 \cdot 5$ \\
\hline
\end{tabular}

Mean values were significantly different from those at the beginning (paired samples test): ${ }^{*} P=0.036,{ }^{* \star} P=0.058$. † For details of diets and procedures, see pp. 11-12.

Table 2. Average percentages of $A R$ homologues $C 17: 0,19: 0,21: 0,23: 0$ and 25:0 in plasma and erythrocyte membranes $(n 8)$ after whole-grain rye and wheat intake, and the ratio of different homologues in plasma and erythrocytes (Mean values with their range $(95 \% \mathrm{Cl})$ )

\begin{tabular}{|c|c|c|c|c|c|}
\hline & C17:0 & C19:0 & C21:0 & C23:0 & C25:0 \\
\hline Plasma (\%) & $\begin{array}{l}13 \\
(6,16)\end{array}$ & $\begin{array}{l}34 \\
(32,35)\end{array}$ & $\begin{array}{l}34 \\
(31,42)\end{array}$ & $\begin{array}{l}14 \\
(13,14)\end{array}$ & $\begin{array}{c}5 \\
(4,9)\end{array}$ \\
\hline Erythrocyte membranes (\%) & $\begin{array}{c}5 \\
(3,9)\end{array}$ & $\begin{array}{l}31 \\
(28,33)\end{array}$ & $\begin{array}{l}36 \\
(30,41)\end{array}$ & $\begin{array}{l}16 \\
(10,20)\end{array}$ & $\begin{array}{l}12 \\
(10,13)\end{array}$ \\
\hline Plasma/erythrocyte membranes & $\begin{array}{c}3.0^{* *} \\
(1.6,4.9)\end{array}$ & $\begin{array}{c}1 \cdot 1^{*} \\
(1 \cdot 0,1 \cdot 2)\end{array}$ & $\begin{array}{c}0.94 \\
(0.85,1.0)\end{array}$ & $\begin{array}{c}0.89 \\
(0.68,1.4)\end{array}$ & $\begin{array}{r}0.50^{\star *} \\
(0.29,0.81)\end{array}$ \\
\hline
\end{tabular}

The ratio was significantly different (paired samples test): ${ }^{\star} P<0.05,{ }^{\star \star} P<0.001$. 
products in Group I. This suggests that AR could be stored in erythrocytes and probably in other tissues, and their liberation from tissues could explain AR present in plasma after avoiding whole-grain products. After intake of whole-grain rye and wheat products a clear increase in plasma AR levels was seen in all but one subject. Erythrocyte membrane AR levels increased significantly in all subjects to the same level or higher than plasma. In Group II, plasma and erythrocyte membrane AR levels remained stable, and this stability can be an advantage if $\mathrm{AR}$ are used as a biomarker. Higher plasma and erythrocyte membrane AR concentrations after the second week in Group I compared to Group II could be explained by higher whole-grain rye product intake. Storage of AR in body tissues during steady intake could also explain lower levels of AR in Group II. No AR were detected in plasma or erythrocyte membranes from the subject following a gluten-free diet that included no rye, wheat or barley cereals, which indicates that intake of AR from other sources apart from whole-grain rye and wheat is nil.

AR homologue compositions were calculated as an average of eight subjects, reflecting the homologue patterns after both rye and wheat bread intake. The mixed pattern can be seen when compared to the literature values of AR homologues in rye and wheat grains (Ross et al. 2003d). We found that longer-chain $\mathrm{AR}$ are incorporated into erythrocyte membranes in a higher proportion than shorter-chain AR. This result is in agreement with previous in vitro studies (Kozubek, 1989). AR have high octanol-water partition coefficients $(\log \mathrm{P}$ o/w), being about 11 for C19:0 (Kozubek, 1995), and are therefore easily incorporated into the membranes. A higher proportion of longer-chain AR in membranes can have relevance when their biological properties are considered.

This study did not address the kinetics of AR in plasma and erythrocytes or provide data to correlate the plasma and erythrocyte membrane AR concentrations to the intake of rye bread or AR from the diet. Such studies are under way. A small number of subjects sets limits to the statistical calculations performed in this study. This study suggests that AR concentrations in plasma and erythrocyte membranes react to the changes in the diet and supports the usability of AR as biomarkers of wholegrain rye and wheat. Erythrocyte membrane AR concentrations could reflect long-term AR and therefore wholegrain rye and wheat intake and could be more suitable as their long-term biomarkers compared to plasma. To confirm this idea, larger, dose-dependent studies are needed.

\section{Acknowledgements}

We thank PhD José Luis Peñalvo García for providing invaluable help during data interpretation. We acknowledge the financial support from the Sigrid Jusélius Foundation, Helsinki, Finland and Finska Läkaresällskapet, Helsinki, Finland.

\section{References}

Adlercreutz H (2002) Phyto-oestrogens and cancer. Lancet Oncol 3, $364-373$.

Bieri JG, Tolliver TJ \& Caliguani BS (1979) Simultaneous determination of a-tocopherol and retinol in plasma and red cells by high performance liquid chromatography. Am J Clin Nutr 32, 2143-2149.

Kamal-Eldin A, Pouru A, Eliasson C \& Åman P (2001) Alkylresorcinols as antioxidants: hydrogen donation and peroxyl radical-scavenging effects. J Sci Food Agric 81, 353-356.

Kantor LS, Variyam JN, Allshouse JE, Putnam JJ \& Lin B-H (2001) Choose a variety of grains daily, especially whole grains: a challenge for consumers. J Nutr 131, 473S-486S.

Kozubek A (1987a) The effect of 5-(n-alk(en)yl)resorcinols on membranes. I. Characterization of the permeability increase induced by 5 (n-heptadecenyl)resorcinol. Acta Biochim Pol 34, 357-367.

Kozubek A (1987b) The effect of 5-(n-alk(en)yl)resorcinols on membranes. II. Dependence of the aliphatic chain length and unsaturation. Acta Biochim Pol 34, 387-394.

Kozubek A (1989) Detergent-like effect of phenolic lipids on biological membranes. Acta Univ Wratisl 868, 27-32.

Kozubek A (1995) Determination of octanol/water partition coefficients for long-chain homologs of orcinol from cereal grains. Acta Biochim Pol 42, 247-251.

Kozubek A, Nietubyc M \& Sikorski AF (1992) Modulation of the activities of membrane enzymes by cereal grain resorcinolic lipids. Z Naturforsch 47, 41-46.

Kozubek A \& Tyman JHP (1999) Resorcinolic lipids, the natural non-isoprenoid phenolic amphiphiles and their biological activity. Chem Rev 99, $1-25$.

Linko A-M, Parikka K, Wähälä K \& Adlercreutz H (2002) Gas chromatographic-mass spectrometric method for the determination of alkylresorcinols in human plasma. Anal Biochem 308, 307-313.

Ross AB, Chen Y, Frank J, Swanson JE, Parker RS, Kozubek A, Lundh T, Vessby B, Åman P \& Kamal-Eldin A (2003a) Cereal alkylresorcinols elevate g-tocopherol levels in rats and inhibit g-tocopherol metabolism in vitro. $J$ Nutr 134, 506-510.

Ross AB, Kamal-Eldin A \& Åman P (2003b) Dietary alkylresorcinols: absorption, bioactivities and possible use as biomarkers of whole grain wheat and rye rich foods. Nutr Rev 62, 81-95.

Ross AB, Kamal-Eldin A, Lundin EA, Zhang JX, Hallmans G \& Åman P (2003c) Cereal alkylresorcinols are absorbed by humans. J Nutr 133, 2222-2224.

Ross AB, Shepherd MJ, Schüpphaus M, Sinclair V, Alfaro B, KamalEldin A \& Åman P (2003d) Alkylresorcinols in cereals and cereal products. J Agric Food Chem 51, 4111-4118.

Simon E, Gariepy J, Cogn A, Moatti N, Simon A \& Paul J-L (2001) Erythrocyte, but not plasma, vitamin E concentration is associated with carotid intima-media thickening in asymptomatic men at risk for cardiovascular disease. Atherosclerosis 159, 193-200.

Slavin J (2003) Why whole grains are protective: biological mechanisms. Proc Nutr Soc 62, 129-134.

Slavin JL, Jacobs D, Marquart L \& Wiemer K (2001) The role of whole grains in disease prevention. $J$ Am Diet Assoc 101, 780-785. 